\title{
A neurological complication of inferior petrosal sinus sampling during investigation for Cushing's disease: a case report
}

\author{
Nigel D C Sturrock, William J Jeffcoate
}

\begin{abstract}
A 45 year old woman with hirsutism was found to have classic biochemical features of ACTH dependent Cushing's disease, with partial cortisol suppression in response to dexamethasone. As no pituitary adenoma could be visualised by $C T$ or MRI, she proceeded to bilateral simultaneous inferior petrosal sinus sampling before possible surgery. During the course of this procedure she had a stroke affecting the brainstem at the level of the pontocerebellar junction. This complication of petrosal sinus sampling has been previously described but is not widely recognised; the procedure should only be undertaken when results of less invasive tests are equivocal.
\end{abstract}

(F Neurol Neurosurg Psychiatry 1997;62:527-528)

Keywords: petrosal sinus sampling; Cushing's syndrome; complications

Defining the cause of Cushing's syndrome is an essential process in the selection of optimal therapy for the individual patient. The presence or otherwise of detectable ACTH, the pattern of response to dexamethasone suppression, and the results of imaging allow the correct diagnosis to be made in most cases, but some authorities recommend whole body or selective petrosal sinus sampling in cases of uncertainty. ${ }^{1}$ This is indicated to confirm the pituitary source of ACTH and may assist lateralisation of the adenoma. However, petrosal sinus catheterisation may sometimes (although rarely) be associated, with appreciable morbidity as illustrated in this present case.

Department of
Diabetes and

Eiabetes and

Hospital, Hucknall

Road, Nottingham, UK

N D C Sturrock

W J Jeffcoate

Correspondence to:

Dr Nigel D C Sturrock

Department of Diabetes and

Endocrinology, City

Endocrinology, City

Nottingham, NG5 1PB, UK.

Received 31 May 1996

and in revised form

28 November 1996

Accepted 23 January 1997
A 45 year old white woman presented in 1991 with a 20 year history of excess hair on her ilised and had no other overt stigmata of Cushing's syndrome. Her serum testosterone was $2 \cdot 1 \mathrm{nmol} / 1$ (normal range $<2 \cdot 8$ ) and hormone binding globulin $43 \mathrm{nmol} / 1$ (normal $50-80$ ), but she had a raised 24 hour urin free cortisol at $1060 \mathrm{nmol} / 24$ hours (normal
80-350). A $1 \mathrm{mg}$ overnight dexamethasone suppression test was suggestive of Cushing's syndrome (0900 serum cortisol $376 \mathrm{nmol} / \mathrm{l}$ ) and further urinary free cortisols were raised (1068, 1399, and $1980 \mathrm{nmol} / 24$ hours). Serum cortisol (pretreatment $824 \mathrm{mmol} / \mathrm{l}$ ) was partially suppressed by low dose $(0.5 \mathrm{mg}$ four times a day) dexamethasone $(309 \mathrm{mmol} / \mathrm{l})$ and was fully suppressed $(69 \mathrm{mmol} / \mathrm{l})$ by high dose (2 $\mathrm{mg}$ four times a day) dexamethasone. Plasma ACTH was measurable at $33 \mathrm{ng} / 1$ (normal 20-80). Radiological imaging by CT of the pituitary region failed to show a discrete pituitary adenoma and adrenal morphology was normal. Other pituitary function was normal. In view of the lack of clinical features of Cushing's syndrome at presentation she was monitored, and over an ensuing 18 month period she developed proximal myopathy, hypertension, and altered mood. During reassessment a peripheral corticotrophin releasing hormone $(\mathrm{CRH})$ test showed an exaggerated response (serum cortisol rose from 416 to $858 \mathrm{mmol} / \mathrm{l}$ ) consistent with pituitary disease, but MRI showed no pituitary abnormality. Bilateral, simultaneous inferior petrosal sinus sampling with CRH stimulation was carried out before possible pituitary surgery in an effort to further confirm pituitary dependent Cushing's disease.

Cannulation was performed with $5 \mathrm{~F}$ catheters and Niopam was used as the radioopaque contrast agent, with $50 \mathrm{ml}$ being available during the placement of each cannula. There was no heparinisation during the procedure. During cannulation of the right side and injection of contrast medium by hand pressure, the patient had pain in her right ear with associated nausea and retching and a consequent, transient, vagally induced fall in her blood pressure (no printout available). The catheter was withdrawn to the jugular vein; an intravenous injection of metoclopramide $(10 \mathrm{mg})$ was given, and the symptoms partially subsided. The catheter was repositioned and after an interval of 20 minutes, basal and CRH $(100 \mu \mathrm{g}$ intravenously) stimulated ACTH samples were obtained simultaneously from right and left petrosal sinuses and the periphery by slow suction. The cannulae were then removed and haemostasis achieved. The total duration of the procedure was two hours. Two hours after returning to the ward she devel- 
Brainstem MRI showing an ill defined area of high signal at the right pontomedullary junction (arrowed).

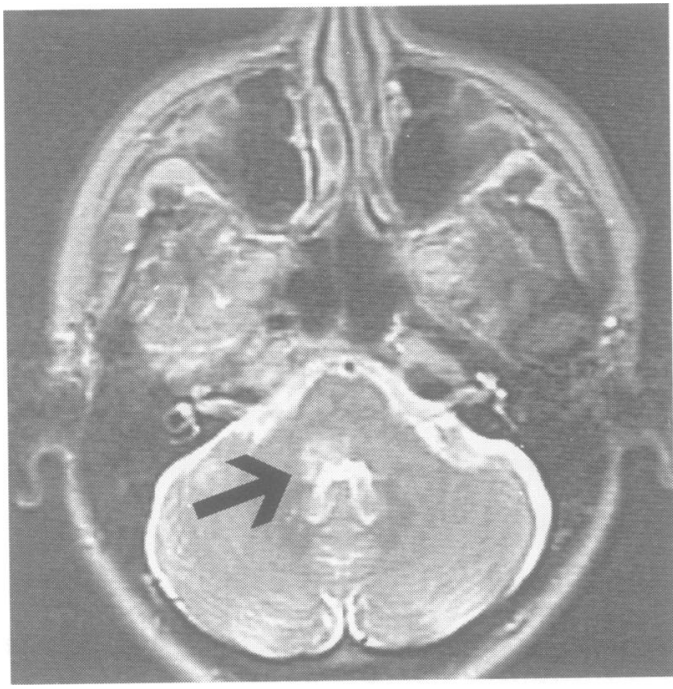

oped difficulty swallowing due to loss of the gag reflex and reduced palatal movement on the right, right lower motor neuron VIth and VIIth nerve palsies, horizontal nystagmus to the right, and contralateral sensory deficit. Her right arm was ataxic but there were no other limb motor signs. Brainstem MRI confirmed an ill defined area of high signal at the pontomedullary junction on the right in keeping with probable venous infarction (fig).

She required gastrostomy feeding until her swallowing had improved. Six months later she had largely recovered but was still unable to walk heel to toe and had a feeling of fullness in the right ear and disturbed temperature sensation in her left arm. Her Cushing's syndrome remains untreated.

\section{Discussion}

The inferior petrosal sinus runs vertically, 2 to $3 \mathrm{~cm}$ from the anteromedial wall of the internal jugular vein until it curves medially towards the cavernous sinus. There are a few connections to the dural venous plexus arising from it. Neurological complications of bilateral petrosal sinus sampling are rare. Seyer et $a l^{2}$ recently reported the development of a VIth nerve palsy with associated hemiparesis in a 14 year old boy undergoing this procedure. The largest series review by Miller et $a l^{3}$ quotes an incidence rate of $0.2 \%$ in a centre carrying out about 50 procedures a year. As in our case, $5 \mathrm{~F}$ catheters were used. They reported four patients who developed disparate neurological symptoms of varying duration from hours to persistent. Sites of damage included the pons and IVth ventricle and the medial medulla. The reason for the procedure to be complicated by a cerebrovascular accident in the brainstem is not immediately obvious, ${ }^{4}$ although it must be concluded that infarction results from the temporary disturbance to venous flow. Ear pain as elicited in our case is attributed to periosteal pain of the jugular bulb indicating that the catheter is beyond the inferior petrosal sinus. ${ }^{5}$ In our patient, contrast did flow after injection suggesting that we had not completely occluded the sinus. The petrosal sinus is unlikely to be completely occluded by the cannulae, but it is possible that contrast injection could precipitate venous hypertension and that this could result in brainstem venous thrombosis in a condition such as Cushing's syndrome, which is associated with hypercoagulability. We now routinely heparinise our patients. It is also possible that any vasovagal reaction complicating local trauma and pain could contribute to the process of infarction by causing a temporary diminution of brain stem blood flow.

Although petrosal sinus catheterisation may provide essential information in the investigation of Cushing's syndrome,${ }^{6}$ the possibility of very occasional but devastating complications should be remembered.

1 Trainer PJ, Rees LH. Cushing's syndrome: diagnosis and rainer PJ, Rees LH. Cushing's syndrome: diagnosis and differential diagnosis. In: Bouloux P-MG, Rees LH, eds. Diagnostic tests in endocrinology and diaber

2 Seyer H, Honegger J, Schott W, Kulche M, Huk WJ, Fahlbusch R, Frisch H. Raymond's syndrome following petrosal sinus sampling. Acta Neurochir (Wien) 1994; 131:157-9.

3 Miller DL, Doppman JL, Peterman SB, Nieman LK, Oldfield EH, Chang R. Neurologic complications of petrosal sinus sampling. Radiology 1992;185:143-7.

4 Huang YP, Wolf BS, Antin SP, Okudera T. The veins of the posterior fossa-anterior or posterior draining group. American fournal of Radiology 1968;104:36-56.

Doppman JL, Krudy AG, Girton ME, Oldfield EH. Basilar venous plexus of the posterior fossa: a potential source of venous plexus of the posterior fossa: a potiolog 1985;155: error 8 .

6 Oldfield EH, Doppman JL, Nieman LK, Chrousos GP, Miller DL, Katz DA, et al. Petrosal sinus sampling with and without corticotropin-releasing hormone for the differential diagnosis of Cushing's syndrome. $N$ Engl f Med 1991;325:897-905. 